\title{
Remembering the past and imagining the
}

\section{future: A role for nonvisual imagery in the everyday cognition of the blind and sighted}

\author{
Alison F. Eardley and Linda Pring \\ Psychology Department, Goldsmiths College, University of London
}

Corresponding Author:

Dr Alison Eardley

Centre de Recherche en Géomatique

Université Laval

0744 Pavillon Louis-Jacques-Casault Québec G1K 7P4

Canada

Telephone number:

+1 (418) 6562131 ext. 3652

Fax number:

$+1(418) 6563607$

E-mail address:

alison.eardley.1@ulaval.ca

Running title: Imagery use in everyday cognition

Key words: Imagery, working memory, future thinking, autobiographical memory, generativity, visually impaired 


\begin{abstract}
$\underline{\text { Abstract }}$
Images can be generated in all sensory modalities. Nevertheless, research on the everyday use of mental imagery, for example in autobiographical memory tasks, has suggested that it is only visual images which facilitate memory retrieval (e.g. Williams et al., 1999). If this is the case, individuals born without sight may be forced to rely more on verbal encoding (Goddard \& Pring, 2001). This paper explores the presence and everyday role of nonvisual sensory imagery in 16 individuals with and 16 without sight. Using a cue word paradigm, contrary to previous research, experiment 1 suggested that for both the blind and sighted nonvisual imageries have a significant a role to play in the generation of autobiographical memories. These results were reinforced by similar findings in experiment 2 , which used the same cue word method to explore the role of visual and nonvisual (auditory) imagery when generating future events. The results refute the claim 'useful' imagery in everyday tasks is exclusively visual.
\end{abstract}




\section{$\underline{\text { Acknowledgements }}$}

This work was completed whilst the first author was supported by an ESRC Doctoral studentship (R42200124139). Research expenses were funded by a University of London Central Research Fund Grant. We would like to thank all those who kindly participated in this experiment. Thank you also to the RNIB, Guide Dogs for the Blind and National Library for the Blind for their assistance in participant recruitment. Thanks also to Dr Geoffrey Edwards \& Dr Clare Davies for their helpful comments on an earlier draft of this paper. 
When people are asked to describe their images, they will often report them as vivid and experienced in all sense modalities (e.g. Betts, 1909; Johnson, 1980; Cornoldi, Calore \& Pra-Baldi, 1979; Kerr \& Johnson, 1991). Indeed, there is now a substantial body of research linking mental imagery function with the primary perceptual processing areas not only for 'visual' imagery (e.g. Farah, 1988; Kosslyn \& Ochsner, 1994; Kosslyn, Pascual-Leone, Felician, Camposano, Keenan, Thompson et al., 1999) but also for nonvisual imageries (e.g. Halpren \& Zatorre, 1999; Levy, Henkin, Lin, Hutter \& Schellinger, 1999). Thus, imagery is a cross-modal experience for which it is general agreed that although it is not synonymous with perception, they are closely connected (e.g. Kosslyn, 1994; Pylyshyn, 2002). Although there has now been considerable research exploring how imagery works, there is a less well defined literature exploring what role imagery plays in everyday cognition.

One way in which it has been suggested which imagery may serve everyday cognition is by facilitating the retrieval of information from memories of complex events, specifically, from autobiographical memory (Conway, 1988, 1996; Conway \& Pleydell-Pearce, 2000). Autobiographical memory is memory for information related to the self (Brewer, 1986). It is comprised of biographical and personally experienced events and facts. It includes memory for the names of teachers whilst at school; for the dates during which the individual was employed at place 'a', 'b' and 'c'; it involves memory of going on holiday to New York, and the specific memory of being in Time Square on one particular day during that holiday. It has been suggested that a pool of sensory-perceptual and spatio-temporal event features make up the lowest level in the organisational hierarchy of autobiographical memory - the event specific knowledge (ESK) base (Conway \& Rubin, 1993). These specific events, to which these pieces of information relate, exist over minutes or hours. For example, 
the first visit to Time Square during a visit to New York. They do not exist as an independent, discrete unit stored in a holistic form. Rather, memories for specific events are constructed.

It is thought that imagery is crucial to the process of remembering specific autobiographical events (see Brewer, 1986; 1988b; Conway, 1988; 1992; Robinson, 1992; Anderson, 1993 cited by Conway \& Pleydell-Pearce, 2000, Williams, 1988). Conway (2001) suggests a very direct relationship between sensory-perceptual episodic memory and autobiographical memory's event related knowledge base. Conway argues that episodic memories are only retained when they become linked to more permanent pre-existing autobiographical memory structures. In other words, if the sensory-perceptually encoded episodic event has salience for understanding of the self then the sensory perceptual information will be subsumed into the 'event specific knowledge' pool.

Despite the evidence indicating that imagery is experienced in multiple sensory modalities, researchers have almost always concluded that it is visual imagery that plays the crucial role in autobiographical memory. It seems that when participants are asked to describe details of events that they remember, the information is almost always in the form of visual images (Anderson (1993 - cited by Conway \& PleydellPearce, 2000). Visual imagery may be used to elicit more details about an event (Robinson, 1992); the presence of visual imagery may also make a memory feel more vivid (Rubin, Schrauf \& Greenberg, 2003). In line with this, recent brain imaging research has found activation within the occipital cortex, during autobiographical memory retrieval (Conway, Turk, Miller, Logan, Nebes, Meltzer \& Becker, 1999; Conway, Pleydell-Pearce \& Whitecross, 2001; Conway, Pleydell-Pearce, Whitecross 
$\&$ Sharpe, 2003). In a review of the neuropsychological data, Greenberg \& Rubin (2003) conclude that visual imagery is crucial to autobiographical memory function.

Brewer (1988a, b) also claims a highly significant role for visual imagery in autobiographical memory, based on a study in which he asked participants to describe autobiographical memories. However, it is interesting to note that as well as containing visual images, Brewer's (1988b) results also indicate a significant proportion of the autobiographical memory descriptions contained strong smells, tastes and textures. It could therefore be argued that when these modalities play a notable role in the original event, they may well be important to the subsequent autobiographical memory retrieval. Nevertheless, in a study looking at the efficacy of different imagery modalities, cued by verbal labels, in stimulating autobiographical memory retrieval, Williams, Healy \& Ellis (1999) did not find tactile, olfactory, gustatory or motor cues had any facilitatory effect on memory retrieval. Rather, only visual imagery was found to have a major role in memory retrieval, with auditory imagery playing a minor role.

An interesting question arises from the general finding that visual imagery is key to autobiographical memory retrieval. If visual imagery alone is involved in specific autobiographical memory retrieval, how will this affect the retrieval of such memories by individuals born totally blind? If vision were necessary for optimum retrieval of all autobiographical memories, given the proposed significance of autobiographical memory to the function of the 'self' (see Conway \& Plydell-Pearce, 2000), the vision impaired brain would be forced to develop compensatory processes to develop some level of autobiographical memory. Goddard \& Pring explored the issues of specificity and memory retrieval time in both children (Goddard \& Pring, 2001) and 
adults (Pring \& Goddard, 2004) with a profound visual impairment. Goddard \& Pring (2001) suggested that individuals without sight might have more difficulty with specific memories. This conclusion was based on both the large levels of prompting and the paucity of information retrieved by the visually impaired children who participated in the study. A reliance on verbal mediation, for example in the use of verbal 'scripts', was the proposed explanation for this deficit (Goddard \& Pring, 2001). However, this early suggestion was not backed up by a larger, later, study carried out with adults (Pring \& Goddard, 2004). Here, no differences in memory specificity or retrieval time were found in either the cue word task (positive emotional, negative emotional and neutral words) or semi-structured autobiographical memory interviews. In fact, in the semantic autobiographical memory recall task individuals without sight performed better than their sighted counterparts. Whilst this may seem to contradict the earlier findings (Goddard \& Pring, 2001), a proportion of the children in the first study had additional learning difficulties which may have affected their performance on this task. Pring \& Goddard (2004) concluded that those born with and without sight may actually be using similar processes for autobiographical memory generation.

This conclusion differs from the one reached by Ogden \& Barker (2001). They reported that whilst sighted participants describe mainly visual features (in line with the findings of Williams et al., 1999), the early blind reported mainly tactile, auditory and spatial features. Nevertheless, the research on autobiographical memory in individuals with a visual impairment seems to agree that neither are they impaired in their ability to retrieve specific memories, nor do they require longer retrieval times. Goddard \& Pring (2001) explain these findings by proposing a more major role for verbal processing. 
Experiment 1 explores the role of sensory imagery - visual and nonvisual - in the everyday task of remembering one's past. Adapting Williams et al.'s (1999) cueword task methodology, blind and sighted participants are asked to generate autobiographical memories in response to eight each of visual, auditory, tactile and low-imagery abstract words (taken from Eardley \& Pring, in prep). If Goddard \& Pring's (2001) verbal mediation hypothesis is correct, then it is expected that, similar to their study, no differences will be found in either specificity or retrieval time between those with and without sight. Since their hypothesis also suggests a strong role for verbal processing in both groups, correlations between verbal fluency, verbal IQ, and memory specificity will be examined. However, if imageability does enhance recall (Williams, 1988; Williams et al., 1999 - Experiment 1) and in view of both Ogden \& Barker's (2001) findings and the fact that those with and without sight rate the imageability of the four word groups differently (see Eardley \& Pring, in prep), differences might be expected in the facility and specificity with which those with and without sight retrieve autobiographical memories in response to the word modes, even if no overall differences in specificity and retrieval time are found.

\section{$\underline{\text { Experiment 1 }}$}

\section{Method}

\section{Participants}

Sixteen sighted adults and sixteen individuals who were either born totally blind, or 
were profoundly visually impaired from infancy participated in this study. Participants in each group were matched for age, gender, verbal IQ and verbal fluency. Of those born totally blind or profoundly visually impaired from early infancy, 4 were male and 12 female. The mean age of participants was: 50.69 (s.d. 14.13) and the mean verbal IQ (WAIS-RNI) was 115.38 (7.23). The mean verbal fluency score was 18.35 (5.38). The age at which participants lost their sight, their levels of sight before and following the loss and the medical diagnosis are detailed in Table 1 below.

(Table 1 about here)

The sighted participants all had normal or corrected to normal vision. There were 4 male participants and 12 female participants and the mean age of participants was 47.94 (s.d. 12.00; range: 26-71). An independent measures t-test revealed that there was no difference between the ages of the two groups $(\mathrm{t}(30)=0.59, \mathrm{p}>0.1)$. Verbal IQ measures provided a mean score of 115.69 (12.55). An independent measures ttest indicated that the groups did not differ on IQ $(\mathrm{t}(29.13)=0.86, \mathrm{p}>0.1)$. The mean verbal fluency score of participants was 16.58 (4.07). An independent measures t-test demonstrated that verbal fluency did not differ across groups $(\mathrm{t}(30)=1.05, \mathrm{p}>0.1)$.

\section{Materials}

Three sets of high imagery sensory words and one set of low imagery abstract words were selected (see Eardley \& Pring, in prep). The words in the visual group were: Rainbow, Sunset, Clown, Moon, Mountain, Painting, Butterfly and Poster. The auditory words were: Ticking, Thunder, Whisper, Dog Bark, Bell, Laughter, Applause, and Fire Alarm. The tactile words were: Sand, Fur, Slime, Ice, Wool, 
Snow, Cashmere, and Tree Bark. The abstract words were: Worth, Knowledge, Duty, Greed, Attitude, Thought, Upkeep and Moral.

A stopwatch was used to record the response latencies.

\section{Procedure}

Participants were told that the research was interested in their memory for events that happened in their lives. They were told that they would hear a number of words, and for each one they would be asked to remember an event from their own lives that the word reminded them of, as quickly as possible. The event could have occurred at any time in their life, and that it could be trivial or significant. It was emphasised that the memory they describe needed to be for a specific event that occurred on one particular occasion. An example was given to distinguish between a specific event and a general event. The experimenter suggested that they might be asked to think of a specific event that the word "party" party reminded them of. They were then told "you could respond: "my birthday party last year, when my friend made me a really lovely chocolate cake". It was also pointed out that a response such as "my birthday parties where we eat lots of cake" would not be specific because it does not refer to one particular occasion. Participants were told to try to describe a different memory for each cue word.

Following this, the experimental procedure was briefly summarised again, emphasising that they should think of a specific event from their lives, as quickly as they could. They were told that once they had thought of something, they should say out loud 'stop' or 'yes'. They were then told that they would have to briefly describe the event they have remembered. Participants were then given an example. All cue 
words were phrased within a question, which emphasised the need to think of a specific event, so the example was: "can you think of a specific event that happened on one particular day that coffee reminds you of?" Following the examples, participants were told that they would have a maximum of 45 seconds to retrieve a memory. They were told not to worry about the time, that it would actually feel quite long when they were trying to think of a memory. They were also told that some cue words would be easier than others, and not to worry if they didn't have a memory in response to a particular word. If they failed to generate a memory, the experimenter simply moved on to the next word. If a participant failed to generate a specific memory within the time period, a latency of 45 seconds was marked. If a participant generated a general image, they were encouraged to try and think of a specific image. Irrespective of whether or not they achieved this, a latency of 45 seconds was recorded.

Participants completed three practice trials and then proceeded to the experimental task. Words were presented in two blocks of 16, with a short verbal task (verbal fluency) in the middle.

Scripts were scored for specificity where by they were given $S$ for specific, $G$ for general, $\mathrm{N}$ for non-autobiographical and $\mathrm{F}$ when participants failed to generate an event of any kind. A quarter of the scripts were double marked by a researcher blind to the experimental hypothesis. 


\section{Inter-rater reliability}

Cohen's Kappa was $0.81, \mathrm{p}<0.001$. This indicated an excellent level of inter-rater reliability.

\section{$\underline{\text { Results }}$}

\section{Retrieval time - excluding failures}

When participants failed to generate a specific memory, producing instead either a general memory or a failure to retrieve any memory, this was marked as a 'fail' and a 45 second latency was automatically given. Although this enables the incorporation of the number of specific memories participants retrieved, it augments the actual speed with which memories were retrieved. In order to get a more precise comparison of the time it took individuals with and without sight to retrieve specific memories for each modality of cue word, the response latencies excluding failures were analysed.

(Table 2 about here)

In order to explore the pattern of specific memory generation a 2 (visual status) $\mathrm{x} 4$ (mode) mixed design ANOVA was carried out looking at the time taken to retrieve specific memories. There was no main effect of visual status, although there may have been a trend towards the blind recalling fewer memories than the sighted $(\mathrm{F}(1$, $30)=3.27, p=0.081)$. The main effect of mode was significant $(F(3,28)=11.59$, $\mathrm{p}<0.001)$. The interaction between mode and visual status was not significant ( $\mathrm{F}(3$, 28) $=1.91, \mathrm{p}>0.1)$. 
Bonferonni-corrected pairwise comparisons exploring the main effect indicate simply that participants took significantly longer to generate memories in response to the abstract words as compared to all other word groups (visual, mean difference: 4.41, $\mathrm{p}<0.001$; tactile, mean difference: $4.55, \mathrm{p}<0.001$; auditory, mean difference: 3.72 , $\mathrm{p}<0.001)$. No other differences were found.

\section{Specificity}

Table 3 illustrates the number of specific memories generated by those with and without sight, in each sense modality, and out of a maximum of eight.

(Table 3 about here)

Normality checks on the number of specific memories recalled by participants indicated that whilst the data was approximately normal for participants without sight, the number of specific memories generated by those with sight could not be considered to be normally distributed. This was partly due to the fact that for the sense modalities, sighted participants demonstrated a ceiling effect in the number of specific memories retrieved. In view of this, the following tests are nonparametric. For all of the non-parametric tests reported in this article, excluding correlations, the Monte Carlo method was used to calculate the significance and was adjusted to take into account multiple tests.

Firstly, looking at the difference in the total number of specific memories retrieved by those with and without sight, it can be seen that the sighted retrieve significantly more memories than do those without sight (Mann-Whitney $U=24, z=-3.94, p<0.001$ ). When comparing the number of specific memories retrieved by the two levels of 
visual status for each modality, it can be seen that the sighted retrieve significantly more memories for abstract (Mann-Whitney $\mathrm{U}=29.5, \mathrm{z}=-3.75, \mathrm{p}<0.001$ ), visual (Mann-Whitney $\mathrm{U}=53.5, \mathrm{z}=-2.91, \mathrm{p}=0.004$ ) and auditory (Mann-Whitney $\mathrm{U}=52.5$, $\mathrm{z}=-2.98, \mathrm{p}=0.003$ ) words. For the tactile words, although there may be a trend in the same direction, this result does not reach significance (Mann-Whitney $U=82.5, z=-$ $1.80, \mathrm{p}=0.075)$.

Friedman tests for K-related samples, looking at mode for each level of visual status, were carried out. These showed a significant effect of mode for both the blind (chisquare $(3)=23.59, \mathrm{p}<0.001)$ and the sighted (chi-square $(3)=13.09, \mathrm{p}=0.003)$.

In order to limit the number of post-hoc pairwise comparisons exploring the difference between mode, for those with and without sight, performance on the visual word group was compared to the abstract, tactile and auditory words respectively. Wilcoxon signed ranks tests indicated that fewer specific memories were generated in response to the abstract words than the visual cues for both the blind (WilcoxonRank: $\mathrm{z}=-3.06, \mathrm{p}<0.001$ ) and the sighted (Wilcoxon-Rank: $\mathrm{z}=-2.45, \mathrm{p}=0.016$ ). No other significant differences were found.

\section{Correlations}

Correlations were run between the verbal control measures and the different word categories. In view of the fact that the specificity scores were not normally distributed, Spearmans rho was used for all correlations. For neither the blind nor the sighted did either the verbal fluency or verbal IQ scores significantly correlate with either the number of specific memories retrieved or the speed at which memories were retrieved. Participants with sight showed a trend $(-0.446 ; p=0.053)$ towards a 
negative correlation between verbal fluency scores and the number of specific auditory memories retrieved. However, when Bonferonni corrections are applied for multiple tests, this result is no longer close to significance.

\section{$\underline{\text { Discussion }}$}

Experiment 1 was designed to explore the role of imagery in the retrieval of autobiographical memories in those with and without sight. No differences were found in the pattern of memory retrieval across word modality, for either specificity or retrieval time, between those with and without sight. It was significantly harder and took significantly longer to retrieve a specific memory in response to the abstract words than any of the 'sense' modalities. For neither visual status group were any differences found between either response latency or memory specificity for auditory, visual or tactile words. This result suggests that the visual and nonvisual sensory modalities have an equally significant role to play in cuing autobiographical memories.

For participants without sight, that there was no significant difference between the cuing potential of the visual, auditory and tactile categories of words is somewhat surprising since individuals without sight have less vivid images in response to visual cue words (Eardley \& Pring, in prep). However, a trend towards participants without sight remembering less specific memories, overall, than do sighted participants, was found. This finding is in line with observations made by Goddard \& Pring (2001), and when it is considered in conjunction with the fact that participants without sight remembered equal numbers of visual, auditory and tactile memories, it might suggest 
a reliance on verbal processes. However, if autobiographical memory were verbally mediated then correlations might be expected between performance on measures of verbal ability and autobiographical memory. No such correlations were found between verbal ability and autobiographical memory retrieval time or specificity, for either those with or without sight. In view of these findings, one could conclude that imagery ability seems to facilitate autobiographical memory retrieval.

Yet, if imagery were being used by individuals without sight to cue autobiographical memories, it still raises questions about why an interaction was not found between sensory modality and visual status, since one would expect autobiographical memory retrieval from the visual words to be harder for the blind than the sighted. A tentative explanation is suggested based on the fact that autobiographical memories, as distinct from images, must have relevance to the self. One might conclude that a specific memory generated by a sighted person in response to the cue word "sunset", for example, as well as having a visual component, will also have an emotional significance. If this event is experienced with someone without sight, then although the importance of the visual sensory experience will not be equivalent, it is possible that the emotional importance is. For example, one participant remembered being on a boat with her husband as the sun set. Her memory of the boat experience included enjoying hearing his excitement at the beautiful sunset. At the same time, she was able to experience directly other sensory experiences, for example the feeling of the air and moving on water. In other words, different aspects of the same 'sunset' event will be encoded with different degrees of salience, depending on what the individual relates to. Thus, even though sense specific images for typically visual phenomenon may be less readily available, and less vivid (Eardley \& Pring, in prep), these sensory cue words may have cross-modal connections to other sensory or emotional 
encodings of self-related experiences which result in privileged access to autobiographical memories in individuals without sight, in comparison to lowimagery cue words.

In conclusion, it seems that imagery, visual and otherwise, has an important role to play in the autobiographical memory of the sighted. That participants without sight generate equal numbers of memories in response to visual and nonvisual images is nonetheless problematic. However, if the hypothesis of images associated with visual words is accepted, then it would seem that imagery also has a significant role to play for those born without sight. A second experiment was carried out to explore further this hypothesis.

\section{Experiment 2}

The processes behind remembering past events - autobiographical memory - and imagining future events have been linked (Williams, Ellis, Tyers, Healy, Rose \& MacLeod, 1996; Klein, Loftus \& Kihlstrom, 2002; D’Argembeau \& Van der Linden, 2004). In view of these apparent functional similarities, the evidence for a role for imagery within autobiographical memory strongly suggests that imagery may have some function to play in this future simulation process.

This is not a novel suggestion, a role for imagery has frequently been cited as enabling humans to think about or imagine the future (Neisser; 1976; Shepard, 1978 cited by Conway, 1988). For example, if you are planning a dinner party, how do you decide whom to invite? How do you decide what foods you want to serve? Perhaps the guests will be chosen by imagining how two people may get on, or ways in which 
they would not get on. Similarly, imagining how the foods will taste and how full you might feel at the end of the meal will help choose the menu. The same underlying processes might be evoked when answering simple questions about the future such as "what time will you be home?" and "will you be able to pick up a video on the way?" Advocates of the 'off-line processing' or 'simulation' models argue that similar processes are evoked when carrying out the everyday task of imagining the future as when generating a fictional story (Johnson-Laird, 1983; Harris, 2000), or answering counterfactual questions (see Harris, 2000). In other words, a mental model is created in which the current state of the world is altered according to the question or proposal, and predictions or decisions are made based on that mental model.

Thus, imagining the future is an everyday task which may indeed involve imagery. However, as Conway (1988) rightly points out, the use of imagery as a way to provide information about possible future events evokes additional features other than those which would be required in autobiographical memory tasks, since it requires individuals to imagine the world in a novel way. Taking this link into consideration, it is particularly interesting to note that the research has also suggested that images for imagined events are not only less vivid (Johnson, Foley, Suengas \& Raye, 1988; Arbuthnott, Geelen \& Kealy, 2002) but also they are less strongly linked with primary perceptual processes (see Conway et al., 2003). The fact that images evoked in a future thinking task would be less strongly linked to perception may serve to polarize the role of direct sensory experience. The 'associated' sensory and emotional experiences, which it is suggested the blind participants might be using to generate memories in response to 'visual' cue words, might be less easily accessible when imagining the future because the links to perceptual experience seem to be weakened (Conway et al., 2003). 
Experiment 2 uses the same cue-word methodology to examine the effects of sensory cue words on the generation of events which might happen in the future. Based on the functional link between remembering events from the past and generating events in the future, it is thought that imagery will be found to play a role in this task.

\section{Method}

\section{Participants}

Participants are the same as in Experiment 1, above.

\section{Materials}

The visual, auditory and low-imagery abstract words, detailed in experiment one, were used in experiment two. In order that the experiment duration remained reasonable, tactile words were not included.

A stopwatch was used to record the response latencies.

\section{Procedure}

Participants were told that they were going to have to think up situations or events that might realistically happen to them in the future.

They were told that they would be given a list of cue words and that for each one they would have to try and imagine a specific event that would be reasonably likely to happen to them in the future. In order to reinforce the importance of specificity, all of 
the words were presented in a neutral sentence, for example: "Can you think of a specific event which might realistically happen in the future which Fur reminds you of?" It was stated that it might be something that could happen in the next couple of weeks, months or something that might happen years in the future. It was stressed that it didn't matter if the event was trivial or important, rather what they should focus on was trying to think of something specific that might be reasonably likely to happen.

An example was given in which participants were told that for the cue word choir, they might try to think of a specific event which might happen in the future where they would hear a choir, for example, "attending the choir service on Christmas Eve next year with my family". They were told that "listening to a choir on the radio" was not specific because it did not refer to one particular day. A second example was given, adapted for both groups. Participants without sight were told that if the cue word was "clouds" they might say going on holiday to Scotland and hearing someone describe the clouds during a walk on a sunny day". The example was also suggested to sighted participants, however it was suggested that they would see the clouds during a walk on a sunny day.

'Realistic' was explained by using the cue word 'music' as an example. Participants were told that if their response to this cue word was that Cliff Richard might be a guest at their next birthday party - that would probably be extremely unlikely to happen. However, if they said that they might be going to a Cliff Richard concert, then that might be reasonably likely to happen.

Participants were asked to say 'stop' when they had thought of a specific event, and 
then to describe it to the experimenter. They were also asked to think of a different event for each cue word. It was explained that they would be given a maximum of one minute to think of something, and if they were not able to think of anything in that time, then they would simply move on to the next cue word. Two practice examples were given.

All words were presented in one of two fixed random orders. The order of word presentation for sighted participants was yoked to the order given to participants without sight.

\section{Scoring procedure}

The scripts were scored for specificity using the same principles described in experiment 1 . Twenty five percent of the scripts were double marked by an independent researcher who was blind to the experimental hypothesis. The inter-rater agreement was significant $(\mathrm{p}<0.001)$ and Cohen's Kappa was 0.72. Any future event over which the raters' had disagreed was discussed and agreement reached.

\section{$\underline{\text { Results }}$}

\section{Response latency - excluding failures}


The standard deviations (see Table 4) indicate that there was a considerable amount of difference in the speed with which individuals were able to generate a specific event that might occur on one particular day in the future.

(Table 4 about here)

A $2 \times 3$ mixed ANOVA was carried out. Sphericity could not be assumed and so the Greenhouse-Geisser correction was used. Both the main effect of mode (F $(1.44,60)$ $=3.46, \mathrm{p}=0.055)$ and visual status $(\mathrm{F}(1,30)=3.45, \mathrm{p}=0.073)$ did not quite reach significance. As with the autobiographical memory data, the interaction between mode and visual status is not significant $(\mathrm{F}(1.44,60)=1.19, \mathrm{p}>0.1)$.

\section{Specificity}

As with the autobiographical memory data, normality could not be assumed and as such non-parametric pair-wise comparisons were carried out, using the Monte Carlo method to calculate significance. An exploration of the patterns of memory retrieval indicate an overall difference in specificity (Mann-Whitney $U=24, p<0.001$ ), with those with sight providing more specific future events.

(Table 5 about here)

The significance level was adjusted to take into account multiple tests. They showed that whilst the sighted were more specific than the blind for both abstract (MannWhitney $U=71.5, p=0.029$ ) and visual words (Mann-Whitney $U=67.0, p=0.015$ ), the difference did not quite reach significance for auditory words (Mann-Whitney $\mathrm{U}=83.0, \mathrm{p}=0.068)$. 
Interestingly the Friedman test for K-related samples, looking at mode for each level of visual status, revealed a significant effect of mode for both the blind (chi-square (2) $=16.44, \mathrm{p}<0.001)$ and the sighted (chi-square $(2)=13.90, \mathrm{p}<0.001)$. As with Experiment 1 above, performance on the visual word group was compared to the abstract and auditory words respectively. These comparisons showed that for the sighted, although more specific future events were generated for visual words than abstract (Wilcoxon-Rank: $\mathrm{z}=-2.97, \mathrm{p}=0.002$ ), this was not the case when comparing visual/auditory words (Wilcoxon-Rank: $\mathrm{z}=-0.26, \mathrm{p}>0.1$ ). For participants without sight, the pattern was slightly different. Here, specific future events were more easily generated for the visual words than abstract (Wilcoxon-Rank: $\mathrm{z}=-2.09, \mathrm{p}=0.04$ ). However, the visual words were significantly less likely to elicit a specific event than were the auditory words (Wilcoxon-Rank: $\mathrm{z}=-2.01, \mathrm{p}=0.048$ ).

\section{Correlations}

Nonparametric correlations were carried out using Spearman's rho. There was a trend towards a negative relationship between verbal IQ and the generation time of auditory events ( $\mathrm{r}=-0.483 ; \mathrm{p}=0.058)$. Again, if a Bonferonni correction for multiple tests were used, this result would no longer reach significance. Taken together, these results support the claim that imagery is being used by individuals born without sight. 
Looking at the nonparametric correlations for individuals with sight, there is a significant negative correlation between the number of specific visual events generated and verbal fluency $(\mathrm{r}=-0.572, \mathrm{p}=0.021)$; if a Bonferonni correction were applied this would loose significance. No other correlations reached or approached significance.

\section{$\underline{\text { Discussion }}$}

Comparative to the autobiographical memory task, the future event generation task required a more active imagination component. It was suggested that the effect this would have would be to reduce the usefulness of 'associated' imageries, thus highlighting differences in sensory experience in a way which was not possible for the autobiographical memory task. In line with this prediction, the facilitatory effect of each group of words, for the blind and sighted, mirrored their imageability ratings (see Eardley \& Pring, in prep). The effects of sensory modality on the everyday task of future event generation showed that whilst people with sight have most difficulty in generating future events in response to abstract cue words, no differences are found between the auditory and visual words. In other words, sighted people can make equal use of visual and nonvisual imagery to generate future events. This result mirrors the findings of the autobiographical memory task and strongly suggests that nonvisual sensory imageries, as well as visual imagery, have an important role to play in everyday tasks.

For participants without sight, imageability played a clear role in the level to which the cue words facilitated the generation of a future event. Individuals without sight found it harder to generate future events in response to the abstract words than to the 
visual words; individuals without sight also found it harder to generate a response to the visual words than they did to the auditory words. These results are in line with previous imageability ratings of the words and reflect the fact that for 'visual' experiences non-visual images are sometimes evoked, albeit weaker than the visual images evoked by sighted people (Eardley \& Pring, in prep).

This result supports the claim that both individuals who were blind and sighted were using imagery to facilitate the generation of possible future events. Further reinforcement for this conclusion comes from an examination of the pattern of correlations between the verbal measures and the sense modalities of the cue words. The correlation data demonstrated that, once corrections for multiple tests were applied and similar to the autobiographical memory task, verbal processes had no significant role to play in this task. Thus, there is strong evidence to suggest that nonvisual imageries have a significant role to play in this task, for both the blind and sighted.

\section{$\underline{\text { General Discussion }}$}

The aim of this research was to explore the role of nonvisual imageries in everyday cognition. What is clear from this research is that those born without sight do make use of sensory images since high imagery cue words generate significantly more memories than do lower imagery items. Furthermore, in the sighted, nonvisual imageries, for example tactile and auditory imagery, have been shown to have an important role to play in the retrieval of autobiographical memories and in the generation of future events. In other words, irrespective of visual experience, 
imagery, and not verbal processes, is crucial to the retrieval of autobiographical memories and the way in which the future is imagined or planned for. This is an important finding because although autobiographical memory models, for example Conway (1988, 1996; 2001; see also Conway \& Pleydell-Pearce, 2000), suggest a role for sensory imagery, previous research has only been able to identify a role for visual imagery (e.g. Williams et al., 1999).

It is possible that this model might be expanded further. Experiment 1 tentatively suggested that where sensory experience was limited, for example in response to visual cue words by the blind, emotional imagery may serve a compensatory role for the reduction in sensory stimuli. Evidence already suggests that the way emotional words are understood is in reference to the self and as a consequence, emotionally charged words are much more likely to produce autobiographical memories, even when these are not specifically required (Conway, 1990). Autobiographical memories high in emotionality also evoke significantly more details than do memories in which emotionality is low or nonexistent (Lyman, Bernardin \& Thomas, 1980). In view of this, it is interesting to note that Rubin et al`s (2003) research on autobiographical memory vividness. They suggested that visual imagery might have a special role to play in the vividness of generated images. Rubin et al. (2003) found that, for sighted participants, visual imagery was the best predictor, in multiple regressions, of the degree to which an image was relived. There were a very small number of exceptions to this rule. In these cases visual imagery played no part in the imagery experience and it was emotional imagery which was crucial for reliving the memory. Similarly, Conway \& Bekerian (1988) found that emotional intensity was one of the two main factors predicting the vividness of memories. If emotional imagery does have an important role to play in the retrieval of autobiographical memories in the blind, and 
perhaps also in the sighted, one might ask where these details are stored and how they fit into current autobiographical memory models. Similar to sensory imagery, emotional details may be stored in the event specific knowledge (ESK) base, providing an additional level of representation. If this were the case one might expect emotional memories to have connections to sensory details. However, whilst emotional memories may be more vivid and detailed than are neutral memories, they are not necessarily more laden in sensory detail (Schaefer \& Philippot, 2005). Evidently, further exploration is needed.

Whilst the results of both experiments support the general conclusion that imagery is being used by the blind and sighted, it is still the case that there was a trend towards the sighted generating more specific events, both remembered from the past or projected into the future, than do the blind. This research was carried out with a clinical sample and in view of the extreme rarity of congenital blindness, has achieved a strong sample size. All the same, it should be noted that there were large individual variations both in terms of the time taken to generate a response and also in the number of specific responses given. In view of this, it is possible that a difference in the levels of specificity between the blind and sighted does factor, but was not identified by this research. Previous research has failed to identify such a difference between those with and without sight (Pring \& Godard, 2004; see also Ogden \& Barker, 2001). Thus, even if the trends towards a lack of specificity in the event retrieval and generation reported here were genuine, the large level of individual differences and the previous failures to find such a difference suggest that the effect size is likely to be small, and difficult to demonstrate conclusively. 
Overall, these results provide important evidence showing that nonvisual imagery has a role to play in everyday cognition. Nevertheless, further research is need to attempt to untangle the specific roles of visual and nonvisual sensory imageries, as well as exploring the question of emotional imagery and multimodality in remembering the past and imagining the future. 


\section{$\underline{\text { References }}$}

Arbuthnott, K. D., Geelen, C. B., \& Kealy, K. L. K. (2002). Phenomenal characteristics of guided imagery, natural imagery, and autobiographical memories. Memory \& Cognition, 30, 519-528.

Betts, G. H. (1909). Distribution and function of mental imagery. Oxford: Teachers College, Columbia University.

Brewer, W. F. (1986). What is autobiographical memory? In D. C. Rubin (Ed.), Autobiographical memory. Cambridge: Cambridge University Press.

Brewer, W. F. (1988a). Memory for randomly sampled autobiographical events. In U. Neisser, \& E. Winograd, (Eds.), Remembering reconsidered: Ecological and traditional approaches to the study of memory. Cambridge: Cambridge University Press.

Brewer, W. F. (1988b). Qualitative analysis of the recalls of randomly sampled autobiographical events. In M. M. Gruneberg, P. E. Morris, \& R. N. Sykes, (Eds.), Practical aspects of memory: Current research and issues. Volume 1: Memory in everyday Life. Chichester: John Wiley \& Sons.

Conway, M. A. (1988). Images in autobiographical memory. In M. Denis, J. Engelkamp, \& J. T. E. Richardson, (Eds.), Cognitive and neuropsychological approaches to mental imagery. Lancaster: Martinus Nijhoff Publishers. 
Conway, M. A. (1990). Conceptual Representation of Emotions: The Role of Autobiographical Memories. In Gilhooly, K. J., Keane, M. T. G., Logie, R. H. \& Erdos, G. (Eds) Lines of thinking: reflections on the psychology of thought. Volume 2 Chichester: John Wiley \& Sons Ltd.

Conway, M. A. (1992). A structural model of autobiographical memory. In: M. A. Conway, D. C. Rubin, H. Spinnler, \& W. A. Wagenaar (Eds.), Theoretical perspectives on autobiographical memory. Dordrecht: Kluwer Academic.

Conway, M. A. (1996). Autobiographical knowledge and autobiographical memories. In D. C. Rubin, (Ed.), Remembering our past. Cambridge: Cambridge University Press.

Conway, M. A. (2001). Sensory-perceptual episodic memory and its context: autobiographical memory. Philosophical Transactions of The Royal Society-Series $B, 356,1375-1384$.

Conway, M. A., \& Bekerian, D. A. (1988). Characteristics of vivid memories. In M. M. Gruneberg, P. E. Morris, \& R. N. Sykes, (Eds.), Practical aspects of memory: Current research and issues. Volume 1: Memory in everyday life. Chichester: John Wiley \& Sons.

Conway, M. A., \& Pleydell-Pearce, C. W. (2000). The construction of autobiographical memories in the self-memory system. Psychological Review, 107, 261-288. 
Conway, M. A., Pleydell-Pearce, C. W., \& Whitecross, S. E. (2001). The neuroanatomy of autobiographical memory: A slow cortical potential study of autobiographical memory retrieval. Journal of Memory and Language, 45, 493-524.

Conway, M. A., Pleydell-Pearce, C. W., Whitecross, S. E., \& Sharpe, H. (2003). Neurophysiological correlates of memory for experienced and imagined events. Neuropsychologia, 41, 334-340.

Conway, M. A., Turk, D. J., Miller, S. L., Logan, J., Nebes, R. D., Meltzer, C. C., \& Becker, J. T. (1999). A positron emission tomography (PET) study of autobiographical memory retrieval. Memory, 7, 679-702.

Cornoldi, C., Calore, D., \& Pra-Baldi, A. (1979). Imagery ratings and recall in congenitally blind subjects. Perceptual and Motor Skills, 48, 627-639.

D’Argembeau, A., Comblain, C., \& Van der Linden, M. (2003). Phenomenal characteristics of autobiographical memories for positive, negative and neutral events. Applied Cognitive Psychology, 13, 175-186.

Eardley, A. F., \& Pring, L. (submitted). Imagery, modality \& vision: Comparing the subjective experience of sensory images in the blind and sighted.

Farah, M. J. (1988). Is visual imagery really visual? Overlooked evidence from neuropsychology. Psychological Review, 95, 307-317. 
Goddard, L., \& Pring. L. (2001). Autobiographical memory in the visually impaired: initial findings and impressions. British Journal of Visual Impairment, 19, 108-113.

Greenberg, D. L., \& Rubin, D. C. (2003). The neuropsychology of autobiographical memory. Cortex, 39 687-728.

Halpren, A. R., \& Zatorre, R. J. (1999). When that tune runs through your head: A PET investigation of auditory imagery for familiar melodies. Cerebral Cortex, 9 , 697-704.

Harris, P. L. (2000). The work of the imagination. Oxford: Blackwell.

Johnson, R. A. (1980). Sensory images in the absence of sight: Blind versus sighted adolescents. Perceptual and Motor Skills, 51, 177-178.

Johnson, M. K., Foley, M. A., Suengas, A. G., \& Raye, C. L. (1988). Phenomenal characteristics of memories for perceived and imagined autobiographical events. Journal of Experimental Psychology: General, 117, 371-376.

Johnson-Laird, P. N. (1983). Mental models: Towards a cognitive science of language, inference, and consciousness. Cambridge: Cambridge University Press. 
Kerr, N. H., \& Johnson, T. H. (1991). Word norms for blind \& sighted subjects: familiarity, concreteness, meaningfulness, imageability, imagery modality and wordassociation. Behavior Research Methods, Instruments \& Computers, 23, 461-485.

Klein, S.B., Loftus, J., \& Kihlstrom, J. (2002). Memory and temporal experience. The effects of episodic memory loss on an amnesic patient's ability to remember the past and imagine the future. Social Cognition, 20, 353-379.

Kosslyn, S. M. (1994). Image and brain: The resolution of the imagery debate. London: MIT Press.

Kosslyn, S. M., \& Ochsner, K. N. (1994). In search of occipital activation during visual mental imagery. Trends in Neuroscience, 17, 290-292.

Kosslyn, S. M., Pascual-Leone, A., Felician, O., Camposano, S., Keenan, J. P., Thompson, W. L., Ganis, G., Sukel, K. E., \& Alpert, N. M. (1999). The role of area 17 in visual imagery: Convergent evidence from PET and rTMS. Science, 284, 167170.

Levy, L. M, Henkin, R. I., Lin, C. S., Hutter, A., \& Schellinger, D. (1999). Odour memory induces brain activation as measured by functional MRI. Journal of Computer Assisted Topography, 23, 487-498.

Lyman, B., Bernardin, S., \& Thomas, S. (1980). Frequency of imagery in emotional experience. Perceptual and Motor Skills, 50, 1159-1162.

Neisser, U. (1976). Cognition and reality. San Francisco: Freeman. 
Ogden, J. A., \& Barker, K. (2001). Imagery used in autobiographical recall in early and late blind adults. Journal of Mental Imagery, 25, 3\&4, 153-176.

Pring, L., \& Goddard, L. (2004). Autobiographical memory: Insights from individuals with a visual impairment. In S. Ballesteros Jiménez \& M. A. Heller (Eds.), Touch, Blindness \& Neuroscience. Madrid: Universidad Nacional de Educacion a Distancia.

Pylyshyn, Z. W. (2002). Mental imagery: In search of a theory. Behavioural and Brain Sciences, 25, 157-238.

Robinson, J. A. (1992). First experience memories: Contexts and functions in personal histories. In M. A. Conway, D. C. Rubin, H. Spinnler, \& W. A. Wagenaar, (Eds.), Theoretical perspectives on autobiographical memory. London: Kluwer Academic Publishers.

Rubin, D. C., Schrauf, R. W., \& Greenberg, D. L. (2003). Belief \& recollection of autobiographical memories. Memory \& Cognition, 31, 887-901.

Schaefer, A., \& Philippot, P. (2005). Selective effects of emotions on the phenomenal characteristics of autobiographical memories. Memory, 13, 148-160. 
Williams, J. M. G. (1988). General \& specific autobiographical memory and emotional disturbances. In M. M. Gruneberg, P. E. Morris, \& R. N. Sykes, (Eds.), Practical aspects of memory: Current research and issues. Volume 1: Memory in everyday life. Chichester: John Wiley \& Sons.

Williams, J. M. G., Ellis, N. C., Tyers, C., Healy, H., Rose, G., \& MacLeod, A. K. (1996). The specificity of autobiographical memory and imageability of the future. Memory \& Cognition, 24, 116-125.

Williams, J. M. G., Healy, H. G., \& Ellis, N. C. (1999). The effect of imageability and predictability of cues in autobiographical memory. The Quarterly Journal of Experimental Psychology, 52A, 555-579. 
Table 1: Participant demographics - individuals born totally blind 


\begin{tabular}{|c|c|c|c|c|c|}
\hline & Sex & Age & $\begin{array}{c}\text { Age at loss of } \\
\text { sight }\end{array}$ & Residual sight & Medical Diagnosis \\
\hline 1 & $\mathrm{~F}$ & 50 & Birth & Light/shade & Retinopathy of Prematurity \\
\hline 2 & $\mathrm{~F}$ & 54 & Birth & None & Retinopathy of Prematurity \\
\hline 3 & $\mathrm{M}$ & 66 & Birth & $\begin{array}{l}\text { Light shade till } \\
40\end{array}$ & Optic Atrophy \\
\hline 4 & $\mathrm{~F}$ & 23 & Birth & Light/shade & Retinopathy of Prematurity \\
\hline 5 & $\mathrm{~F}$ & 51 & Birth & Light/shade & Retinopathy of Prematurity \\
\hline 6 & $\mathrm{~F}$ & 23 & Birth & Light/shade & Retinopathy of Prematurity \\
\hline 7 & $\mathrm{~F}$ & 28 & $\begin{array}{c}9 \text { months } 1^{\text {st }} \\
\text { eye, both } 2 \text { yrs }\end{array}$ & None & Retinal Blastoma \\
\hline 8 & $\mathrm{~F}$ & 54 & Birth & None & $\begin{array}{l}\text { Retinitus Pigmentos, } \\
\text { Lebers Atrophy, Kerry } \\
\text { ticomas, Nistagmus }\end{array}$ \\
\hline 9 & $\mathrm{M}$ & 54 & Birth & None & Retinopathy of Prematurity \\
\hline 10 & $\mathrm{~F}$ & 51 & Birth & None & Mother had Rubella \\
\hline 11 & $\mathrm{~F}$ & 58 & Birth & Light/shade & Retinopathy of Prematurity \\
\hline 12 & $\mathrm{M}$ & 64 & Birth & $\begin{array}{l}\text { Used to have } \\
\text { light/shade }\end{array}$ & Congenital Glaucoma \\
\hline 13 & $\mathrm{~F}$ & 55 & $1 \frac{1}{2}$ & None & Unspecified viral infection \\
\hline 14 & M & 58 & Birth & Light/shade & Lebers disease \\
\hline 15 & $\mathrm{~F}$ & 70 & Birth & None & Microphthalmia \\
\hline 16 & $\mathrm{~F}$ & 51 & $\begin{array}{l}18 \text { months - } \\
\text { deterioration } \\
\text { from } 5 \text { months }\end{array}$ & None & Pseudo Glaucoma \\
\hline
\end{tabular}


Table 2: Mean and standard deviations of time taken (in seconds) to retrieve a specific autobiographical memory

\begin{tabular}{|l|l|c|c|c|c|}
\cline { 2 - 6 } \multicolumn{2}{|c|}{} & \multicolumn{4}{c|}{ Mode } \\
\cline { 2 - 6 } \multicolumn{2}{|c|}{} & Abstract & Visual & Tactile & Auditory \\
\hline \multirow{3}{*}{ Visual } & Blind & $14.46(5.96)$ & $10.87(5.86)$ & $9.94(4.01)$ & $9.47(3.99)$ \\
\cline { 2 - 6 } & Sighted & $12.04(4.77)$ & $6.89(3.42)$ & $7.46(3.42)$ & $9.37(3.63)$ \\
\hline
\end{tabular}


Table 3: Mean and standard deviations of number of specific autobiographical memories retrieved, by blind and sighted, for each level of mode (maximum 8)

\begin{tabular}{|l|l|c|c|c|c|}
\cline { 3 - 6 } \multicolumn{2}{c|}{} & \multicolumn{4}{c|}{ Mode } \\
\cline { 2 - 6 } \multicolumn{2}{c|}{} & Abstract & Visual & Tactile & Auditory \\
\hline \multirow{3}{*}{ Visual } & Blind & $3.00(1.26)$ & $5.50(1.59)$ & $6.12(1.93)$ & $6.19(1.22)$ \\
\cline { 2 - 6 } & Status & & & & $7.37(0.81)$ \\
\hline
\end{tabular}


Table 4: Mean and standard deviations of time taken (in seconds) to generate a specific future event

\begin{tabular}{|l|l|c|c|c|}
\cline { 3 - 5 } \multicolumn{2}{c|}{} & \multicolumn{3}{c|}{ Mode } \\
\cline { 2 - 5 } \multicolumn{2}{c|}{} & Abstract & Visual & Auditory \\
\hline \multirow{3}{*}{ Visual } & Blind & $20.10(9.57)$ & $14.36(4.11)$ & $13.83(3.56)$ \\
\cline { 2 - 5 } & Status & $14.41(8.23)$ & $11.99(7.51)$ & $13.34(6.73)$ \\
\hline
\end{tabular}


Table 5: Mean number of specific future events generated (Mann-Whitney U test), by blind and sighted, for mode (maximum 8)

\begin{tabular}{|l|l|c|c|c|}
\cline { 3 - 5 } \multicolumn{2}{c|}{} & \multicolumn{3}{c|}{ Mode } \\
\cline { 2 - 5 } \multicolumn{2}{c|}{} & Abstract & Visual & Auditory \\
\hline \multirow{3}{*}{ Visual } & Blind & $4.56(1.41)$ & $5.88(2.00)$ & $6.81(1.05)$ \\
\cline { 2 - 5 } & Status & $6.00(1.86)$ & $7.38(0.96)$ & $7.44(0.89)$ \\
\hline
\end{tabular}

